\title{
Restoration of euthyroidism accelerates bone turnover in patients with subclinical hypothyroidism: a randomized controlled trial
}

\author{
Christian Meier · Müller Beat · Merih Guglielmetti \\ Mirjam Christ-Crain · Jean-Jacques Staub \\ Marius Kraenzlin
}

Received: 24 March 2003 / Accepted: 12 September 2003 / Published online: 16 January 2004

(C) International Osteoporosis Foundation and National Osteoporosis Foundation 2004

\begin{abstract}
This study evaluated the effect of physiological L-thyroxine (L-T4) treatment on bone metabolism in patients with subclinical hypothyroidism. Sixty-six women with subclinical hypothyroidism (TSH $11.7 \pm 0.8 \mathrm{mIU} / \mathrm{l})$ were randomly assigned to receive L-T4 or placebo for 48 weeks. Sixty-one of 66 patients completed the study. Individual L-T4 replacement (mean dosage $85.5 \pm 4.3 \mu \mathrm{g} /$ day) was performed targeting euthyroid thyroid-stimulating hormone (TSH) levels. The primary outcome measure was 24 - and 48week change in markers of bone formation (total and bone alkaline phosphatase [ALP, bone ALP], osteocalcin $[\mathrm{OC}]$ ) and resorption (pyridinoline [PYD] and deoxypyridinoline [DPD], C-terminal cross-linking telopeptide type I [CTX]). Secondary outcomes were 48-week changes in bone mineral density (BMD) of the lumbar spine and hip, measured by dual-energy X-ray absorptiometry. Compared with placebo, L-thyroxine $(n=31)$ resulted in significant activation of bone turnover. Overall, a significant treatment effect was observed for DPD (between-group difference 16.0\%;
\end{abstract}

This work was supported by grants from the Swiss National Science Foundation $(32.27866 .89,32.37792 .93$, and 32.37792.98) and unconditional research grants from Henning Berlin, Sandoz Research, and Roche Research foundations. Presented in part at the 24th annual meeting of the American Society for Bone and Mineral Research, San Antonio, 2002, and at the 84th annual meeting of The Endocrine Society, San Francisco, 2002.

C. Meier $\cdot$ M. Beat $\cdot$ M. Guglielmetti $\cdot$ M. Christ-Crain

J.-J. Staub · M. Kraenzlin

Division of Endocrinology,

Department of Medicine, University Hospitals,

CH-4031, Basel, Switzerland

C. Meier $(\bowtie)$

Bone Research Laboratory,

ANZAC Research Institute, University of Sydney,

NSW 2139 Concord, Australia

E-mail: cmeier@med.usyd.edu.au

Tel.: + 61-2-97679164

Fax: +61-2-97679100
95\% CI, 10.9 to 21.1$)$, CTX $(29.9 \%$; $95 \% \mathrm{CI}, 23.3$ to $36.5)$, and bone ALP $(13.2 \% ; 95 \% \mathrm{CI}, 6.6$ to 19.7$)$ after 24 weeks. At the end of the study, lumbar BMD in the both treatment groups differed by $1.3 \%$ $(95 \% \mathrm{CI},-2.9$ to 0.5$)$ with lower levels in L-thyroxine treated women. Significant difference in BMD between groups was also observed at the trochanter. We conclude that physiological L-thyroxine treatment accelerates bone turnover reflecting early activation of bone remodeling units in the initial replacement of subclinical hypothyroidism. The observed bone loss could be interpreted as an adaptive mechanism on decreased bone turnover in preexistent hypothyroidism, and not as L-thyroxine-induced clinically important bone loss. However, long-term studies are needed to confirm this assumption.

Keywords Bone density - Bone remodeling Replacement - Subclinical hypothyroidism - Thyroxine

\section{Introduction}

The relation between thyroid hormone and bone in overt hyperthyroidism is well established. Hyperthyroidism accelerates bone turnover and shortens the normal bone remodeling cycle, leading to osteoporosis and increased fracture risk. Thyroid hormones are among the most commonly used medications and, according to observational studies, the use of thyroid hormones to suppress pituitary TSH in the treatment of thyroid cancer, goiters, or thyroid nodules seems to have an adverse effect on bone homeostasis, especially in postmenopausal women [1]

While bone remodeling is accelerated in hyperthyroidism, it has been demonstrated that the remodeling cycle in overt hypothyroidism is increased to almost 2 years with an increase in mineralized cortical bone [2] Based on a histomorphometric study, patients with untreated hypothyroidism have a higher mean cortical 
bone width, which in turn, decreases during thyroxine treatment [3]. Some cross-sectional and longitudinal studies $[4,5,6,7,8,9,10]$, but not all $[11,12,13,14,15$, 16], evaluating bone mineral density in patients with overt hypothyroidism have suggested that thyroid hormone replacement could have a deleterious effect on bone mineral density.

Subclinical hypothyroidism ( $\mathrm{SCH})$ has been detected with increasing frequency in recent years with an estimated prevalence of about $5 \%$ to $16 \%$ in the female population. This syndrome is characterized by elevated thyroid-stimulating hormone (TSH) levels in the presence of normal circulating thyroid hormones, thyroxine $\left(\mathrm{T}_{4}\right)$ and triiodothyronine $\left(\mathrm{T}_{3}\right)$ [17]. Though it has been shown that thyroid hormone replacement may be beneficial in patients with $\mathrm{SCH}$, less is known about its potential role on bone remodeling. Only a few studies have evaluated the effect of thyroxine replacement on bone in patients with mild thyroid failure $[18,19,20,21]$. We therefore initiated a doubleblind, placebo- and TSH-controlled study with the aim to investigate the effect of physiological L-thyroxine treatment on bone remodeling in patients with subclinical hypothyroidism.

\section{Subjects and methods}

\section{Study population}

The present study was part of a prospective, double-blind, placebocontrolled trial whose design and patient characteristics have been described previously [22]. Briefly, between September 1993 and May 1997, 66 women with SCH were enrolled in the study. All patients were examined and followed up in the Thyroid Research Unit of the Division of Endocrinology at the University Hospital, Basel, Switzerland. The inclusion criteria were as follows: age 1875 years; TSH level $>5.0 \mathrm{mIU} / 1$ on two consecutive blood tests; exaggerated TSH response $>35 \mathrm{mIU} / 1$ after TRH stimulation; free $\mathrm{T}_{4}$ concentration within the normal range; good general health as assessed by a full medical and endocrine work-up. The exclusion criteria were as follows: pituitary/hypothalamic disorders or other nonthyroidal illnesses; thyroid hormone medication up to 12 months prior to enrollment. Forty-nine of 66 patients had a postmenopausal hormone status with identical ratios between both treatment groups (L-T4: 25/33, and placebo: 24/33). In patients treated with estrogen-replacement therapy (nine in each group) the dose remained unchanged over the whole study period.

The study was terminated early in two participants due to previously unknown serious comorbidities (endometrial cancer, malignant astrocytoma; both assigned L-T4) and in another patient due to rapid progression to clinically overt hypothyroidism (assigned placebo). Two patients on antiresorptive osteoporosis treatment (alendronate, pamidronate) were excluded for further analysis. Apart above specified estrogen replacement therapy in postmenopausal women, none of the patients was on drugs known to affect bone metabolism (i.e., glucocorticoids, statins, calcitonin, anticonvulsants, and vitamin D or analogues).

A total of 61 women were analyzed. The underlying thyroid disorders leading to $\mathrm{SCH}$ consisted of autoimmune thyroiditis $(n=32)$, Graves' disease ( $n=22$, treated with radioiodine, surgery, or with carbimazole), toxic multinodular goiter $(n=2$; treated with radioiodine), and surgically resected goiter $(\mathrm{n}=5)$. The median time after radioactive iodine therapy before entry into the study was 11.0 years (range $1-42$ years). The frequencies of underlying thyroid disorders were equally distributed in the L-T4 and placebo group.

\section{Design and organization of the study}

Eligible patients were sequentially assigned either to the L-T4 treatment group $(n=33)$ or to the placebo group $(n=33)$ according to a predefined randomization list. The study duration for each patient was 50 weeks, including a 2-week run-in phase before starting treatment. During the first 24 weeks, the L-T4 dosage was adapted continuously every 6 weeks in order to achieve an optimal physiological hormone replacement with euthyroid TSH levels (i.e., basal TSH concentration within the reference range [0.1-4.0 mIU/ 1]). L-Thyroxine (Henning Berlin; Berlin, Germany) was given in the fasting state. The dosage was controlled every 6 weeks to ascertain an optimal replacement regimen (mean L-T4 dosage at the end of the study: $85.5 \pm 4.3 \mu \mathrm{g}$ daily, range $50-125 \mu \mathrm{g}$ ). To guarantee blinding, patients in the placebo group received identical-appearing tablets with dosage adjustments in concordance to their randomly assigned patients in the treatment group. The local Ethics Committee for Human Studies approved the study. Written informed consent was obtained from all study participants.

\section{Laboratory measurements}

Measurements of hormones and biochemical markers of bone turnover were assessed at the baseline visit, after 24 weeks, and at the end of the study after 48 weeks. Serum and urine samples were collected in the fasting state between 0800 and 1000 hours, immediately put on ice and processed within $30 \mathrm{~min}$. Thereafter, they were stored at $-70^{\circ} \mathrm{C}$ until measurement. Serum TSH concentration (reference range 0.1 to $4.0 \mathrm{mIU} / \mathrm{l}$ ) was measured by a sensitive immunometric assay (Delfia; Wallac, Turku, Finland). Free $\mathrm{T}_{4}(8.0$ to $23.0 \mathrm{pmol} / \mathrm{l})$ and total $\mathrm{T}_{3}(1.2$ to $3.1 \mathrm{nmol} / \mathrm{l})$ were determined by microparticle enzyme immunoassays IMx (Abbott, Baar, Switzerland). Serum estradiol (follicular phase, 90 to $716 \mathrm{pmol} / \mathrm{l}$; postmenopausal, 37 to $145 \mathrm{pmol} / \mathrm{l}$ ) were measured by an ECL immunoassay (Elecsys; Roche Diagnostics, Basel, Switzerland). Total alkaline phosphatase (ALP) activity was measured according to the IFCC guidelines, using an automated colorimetric assay and para-nitrophenyl phosphate as a substrate at $37^{\circ} \mathrm{C}$ (reference range 31 to $108 \mathrm{U} / 1$; Hitachi System 704 analyzer; Roche Diagnostics, Basel, Switzerland). Bone alkaline phosphatase (bone ALP; reference range 8.0 to $16.6 \mu \mathrm{g} / \mathrm{l}$; Tandem-MP Ostase; Beckman Coulter, Fullerton, USA) and serum osteocalcin (OC; reference range 7.7 to $32.0 \mathrm{ng} / \mathrm{ml}$; ELSA-Osteo; CisBio International, France) were determined by an immunometric assay. Urine pyridinium collagen cross-links (pyridinoline and deoxypyridinoline) were measured by high performance liquid chromatography (HPLC) (Crosslinks; BioRad, Munich, Germany), and the results were expressed in relation to the urinary creatinine. The detection limit for both of the collagen cross-links was $5.0 \mathrm{pmol} / 1$, with a reference range of 60 to $100 \mathrm{pmol} / \mathrm{mmol}$ for pyridinoline/creatinine and 9 to $20 \mathrm{pmol} /$ mmol for deoxypyridinoline/creatinine. Serum C-terminal telopeptides of type I collagen (CTX; reference range 0.13 to $4.1 \mu \mathrm{g} / \mathrm{l})$ was measured on the Elecsys 2010 automated analyzer (Beta-crosslaps; Roche Diagnostic, Rotkreuz, Switzerland) using the $\beta$-crosslaps/serum reagents [23]. The intra- and interassay variation for the various assays used were OC, $5.3 \%$ and $6.2 \%$; ALP, $3.2 \%$ and $4.8 \%$; bone ALP, $6.7 \%$ and $8.1 \%$; pyridinium crosslinks, $4 \%$ and $10 \%$; CTX, $3.4 \%$ and $4.6 \%$; respectively. Urinary calcium and creatinine were assayed using an autoanalyzer (Hitachi, Roche Diagnostics, Rotkreuz, Switzerland). The calcium results were expressed in relation to the urinary creatinine, the reference range being 0.1 to $0.32 \mathrm{mmol} / \mathrm{mmol}$.

\section{Bone density measurements}

Bone mineral density at the lumbar spine and hip (femoral neck, greater trochanter, Ward's triangle) was evaluated by dual-energy X-ray absorptiometry (DXA) using a Lunar Expert densitometer (Lunar, Madison, WI, USA). Lumbar vertebrae with prevalent or 
incident fractures at L1 to L4 or degenerative bone disease were not included in the bone mineral density measurements. To assess the short-term precision of the system in this population, a single repeat measurement in 20 patients was performed [24]. In each case, the patient was removed from the scanner and repositioned between measurements. The coefficient of variation of individual measurements was $1.1 \%$ for the spine, $1.8 \%$ for the femoral neck, $1.7 \%$ for Ward's triangle, and $2.1 \%$ for the trochanteric region.

\section{Statistical methods}

All data are expressed as means \pm standard errors of the mean (SEM). Unpaired $t$-test (two-sided), or Mann-Whitney $U$-test in the case of nonparametric distributions, were used to identify demographic variables showing differences among the groups. Differences of frequencies were tested with the $\chi$-square test or Fisher exact test, as appropriate. To compare study variables during study periods, one-way ANOVA for repeated measures with post hoc comparisons corrected for multiple testing by least squares difference (LSD) was used. Significance was defined as $p<0.05$. Data were analyzed using Statistica for Windows (version 6.0; StatSoft, Tulsa, OK, USA).

\section{Results}

\section{Baseline characteristics}

Table 1 summarizes the baseline characteristics of the 66 study participants. Sixty-one women (mean age

Table 1 Baseline data of the study population $(n=66)$. Characteristics at baseline were not significantly different in either treatment group (analysis was done by intention-to-treat: significance was determined by unpaired $t$-test (two-sided) or by Mann-Whitney $U$-test in nonparametric distribution, and $\chi$-square test or Fisher exact test, as appropriate). Data are mean \pm SEM

\begin{tabular}{|c|c|c|}
\hline Characteristics & $\begin{array}{l}\text { L-T4 group } \\
(n=33)\end{array}$ & $\begin{array}{l}\text { Placebo group } \\
(n=33)\end{array}$ \\
\hline Age (years) & $57.1 \pm 1.8$ & $57.1 \pm 1.9$ \\
\hline Body mass index $\left(\mathrm{kg} / \mathrm{m}^{2}\right)$ & $25.6 \pm 0.7$ & $26.4 \pm 0.7$ \\
\hline Smokers (\%) & $5(15.1 \%)$ & $2(6.1 \%)$ \\
\hline Pre-/postmenopausal & $8 / 25$ & $9 / 24$ \\
\hline Years since menopause & $11.6 \pm 1.6$ & $11.8 \pm 1.4$ \\
\hline Estradiol (pmol/l) & $334.6 \pm 86.7$ & $296.7 \pm 52.4$ \\
\hline Dietary calcium intake (mg/day) & $915.7 \pm 71.8$ & $756.7 \pm 73.4$ \\
\hline TSH (mIU/l) & $14.4 \pm 1.7$ & $11.3 \pm 1.0$ \\
\hline $\mathrm{fT}_{4}(\mathrm{pmol} / \mathrm{l})$ & $11.9 \pm 0.3$ & $12.2 \pm 0.3$ \\
\hline $\mathrm{T}_{3}(\mathrm{nmol} / \mathrm{l})$ & $2.0 \pm 0.1$ & $1.9 \pm 0.1$ \\
\hline Calcil & 2.3 & $2.3 \pm 0.0$ \\
\hline Phos! & $1.1 \pm$ & $1.1 \pm 0.0$ \\
\hline Total & $63.3 \pm 3.6$ & $69.8 \pm 4.8$ \\
\hline $\begin{array}{l}\text { Bone-specific alkaline } \\
\text { phophatase }(\mathrm{U} / \mathrm{l})\end{array}$ & $9.6 \pm 0.7$ & $10.2 \pm 0.8$ \\
\hline Osteocalcin (ng/ml) & 1.7 & $23.3 \pm 1.6$ \\
\hline $\begin{array}{l}\text { C-terminal telopeptide } \\
\text { type I collagen }(\mu \mathrm{g} / \mathrm{l})\end{array}$ & & $0.4 \pm 0.0$ \\
\hline $\begin{array}{l}\text { U-pyridinoline/creatinine } \\
\text { (pmol } / \mathrm{mmol})\end{array}$ & $3 \pm 4.8$ & $68.7 \pm 4.3$ \\
\hline $\begin{array}{l}\text { U-deoxypyridinoline/creatinine } \\
\text { (pmol/mmol) }\end{array}$ & $13.9 \pm 1.0$ & $13.7 \pm 0.9$ \\
\hline U-calcium/creatinine $(\mathrm{mmol} / \mathrm{mmol})$ & $0.3=$ & $0.3 \pm 0.0$ \\
\hline BMD, lumbar spine $\left(\mathrm{g} / \mathrm{cm}^{2}\right)$ & $1.086 \pm 0.032$ & $1.070 \pm 0.036$ \\
\hline BMD, femoral neck $\left(\mathrm{g} / \mathrm{cm}^{2}\right)$ & $0.932 \pm 0.022$ & $0.908 \pm 0.029$ \\
\hline $\mathrm{BMD}$, trochanter $\left(\mathrm{g} / \mathrm{cm}^{2}\right)$ & $0.796 \pm 0.019$ & $0.759 \pm 0.031$ \\
\hline BMD, Ward's triangle $\left(\mathrm{g} / \mathrm{cm}^{2}\right)$ & $0.776 \pm 0.028$ & $0.750 \pm 0.033$ \\
\hline
\end{tabular}

$57.1 \pm 1.3$ years) completed the study as foreseen by the study protocol and were included in the analysis. The two groups of women with $\mathrm{SCH}$ (L-thyroxine, $n=33$; placebo, $n=33$ ), as well as the 61 women in the final analysis (L-thyroxine, $n=31$; placebo, $n=30$ ), were well matched for age, body mass index, smoking habits, estrogen status, and dietary calcium intake (using standardized questionnaires). The patient groups were also similar with respect to thyroid hormone concentrations, biochemical markers of bone turnover, and bone mineral density. Basal TSH levels were mildly to markedly elevated (range 4.7-46.3 mIU/1) with exaggerated TSH response $>35 \mathrm{mIU} / 1$ after $\mathrm{TRH}$ in both treatment groups; peripheral thyroid hormone concentrations $\left(\mathrm{fT}_{4}\right.$, $\mathrm{T}_{3}$ ) were within the lower reference range. According to the WHO definition, the number of patients with lumbar osteoporosis ( $T$-score $<-2.5$ : L-T4, $n=3$, and placebo, $n=2)$ and lumbar osteopenia ( $T$-score -1 to -2.5 : L-T4, $n=15$, and placebo, $n=10$ ) were comparable in both treatment groups $(p=\mathrm{ns})$. Similar proportions were documented for femoral BMD values $(T$-score $<-2.5$ : L-T4, $n=0$, and placebo, $n=1 ; T$-score -1 to -2.5 : L-T4, $n=10$, and placebo, $n=11 ; p=$ ns for both comparisons).

Effect of treatment on thyroid hormone concentrations

To decrease the TSH concentration to the euthyroid reference range, the L-T4 dosage was adapted at 6-week intervals (mean dosage $85.5 \pm 4.3 \mu \mathrm{g}$ daily). In all L-T4-treated patients, TSH levels remained in the euthyroid range for at least the last 24 weeks. Mean serum TSH level at the end of the study was $3.1 \pm 0.3 \mathrm{mIU} / 1$. No patient had a blunted or absent TSH response to thyrotropin-releasing hormone. Peripheral thyroid hormone concentrations increased $\left(\mathrm{fT}_{4}\right)$ and decreased $\left(\mathrm{T}_{3}\right)$ significantly within the reference range. No change in any variable of thyroid function could be seen in the placebo group (Table 2).

Effect of treatment on biochemical markers of bone turnover

In all women, serum biochemical markers of bone formation and resorption were measured at baseline, after 24 weeks, and at the end of the study after 48 weeks. Significant changes of bone markers could be seen in L-T4-treated patients only, whereas placebo-treated patients showed no significant increases during the study period (Table 2).

\section{Bone formation markers}

The mean baseline total alkaline phosphatase (ALP) level for the entire sample $(n=61)$ was within the female reference range. During L-T4 treatment, ALP levels 
Table 2 Parameters before, and after 24 and 48 weeks of treatment with L-T4 $(n=31)$ or placebo $(n=30)$. To compare study variables during L-T4 or placebo treatment, ANOVA with repeated measures was used (analysis was done per protocol). Paired Student's $t$ - test (two-sided) or Wilcoxon signed rank test in the case of nonparametric distributions were applied to evaluate the change in values after 24 and 48 weeks in comparison to baseline within groups. Data are mean \pm SEM

\begin{tabular}{|c|c|c|c|c|c|c|c|}
\hline Parameters & \multicolumn{3}{|c|}{ Treatment with L-T4 $(n=31)$} & \multicolumn{3}{|c|}{ Treatment with placebo $(n=30)$} & $\begin{array}{l}\text { Between-group } \\
\text { comparison } \\
\text { (ANOVA) }\end{array}$ \\
\hline TSH (mIU/l) & $12.8 \pm 1.4$ & $3.6 \pm 0.5^{\mathrm{d}}$ & $3.1 \pm 0.3^{\mathrm{d}}$ & $10.8 \pm 1.0$ & $10.2 \pm 0.7$ & $9.9 \pm 0.6$ & $p<0.0001$ \\
\hline $\mathrm{fT}_{4}(\mathrm{pmol} / \mathrm{l})$ & $11.6 \pm 0.3$ & $16.9 \pm 0.5^{\mathrm{d}}$ & $17.8 \pm 0.8^{\mathrm{d}}$ & $12.0 \pm 0.3$ & $12.4 \pm 0.4$ & $12.3 \pm 0.4$ & $p<0.0001$ \\
\hline $\mathrm{T}_{3}(\mathrm{nmol} / \mathrm{l})$ & $2.0 \pm 0.1$ & $1.7 \pm 0.1^{\mathrm{b}}$ & $1.7 \pm 0.1^{\mathrm{d}}$ & $1.9 \pm 0.1$ & $1.8 \pm 0.1$ & $1.9 \pm 0.1$ & $p=0.002$ \\
\hline Calcium (mmol/l) & $2.3 \pm 0.0$ & $2.3 \pm 0.0$ & $2.3 \pm 0.0$ & $2.3 \pm 0.0$ & $2.3 \pm 0.0$ & $2.3 \pm 0.0$ & $p=0.812$ \\
\hline $\begin{array}{l}\text { Bone-specific } \\
\text { alkaline phosphatase }(\mathrm{U} / \mathrm{l})\end{array}$ & $9.6 \pm 0.7$ & $10.2 \pm 0.8^{\mathrm{a}}$ & $10.2 \pm 0.8$ & $10.2 \pm 0.9$ & $9.2 \pm 0.8$ & $9.8 \pm 0.9$ & $p=0.147$ \\
\hline Osteocalcin $(\mathrm{ng} / \mathrm{ml})$ & $24.7 \pm 1.8$ & $26.2 \pm 1.5^{\mathrm{b}}$ & $25.2 \pm 1.3$ & $22.3 \pm 1.7$ & $22.7 \pm 1.8$ & $22.7 \pm 1.7$ & $p=0.674$ \\
\hline $\begin{array}{l}\text { C-terminal telopeptide } \\
\text { type I collagen }(\mathrm{mg} / \mathrm{l})\end{array}$ & $0.36 \pm 0.04$ & $0.41 \pm 0.05^{\mathrm{b}}$ & $0.39 \pm 0.04$ & $0.35 \pm 0.03$ & $0.32 \pm 0.03^{\mathrm{b}}$ & $0.35 \pm 0.04$ & $p=0.013$ \\
\hline
\end{tabular}

${ }^{\mathrm{a}} p=0.05 ;{ }^{\mathrm{b}} p<0.05 ;{ }^{\mathrm{c}} p<0.005 ;{ }^{\mathrm{d}} p<0.001$

increased progressively after 24 weeks $(p=0.05)$ and 48 weeks $(p=0.004)$. In contrast, no significant change of bone-specific alkaline phosphatase (bone ALP) levels could be observed during L-T4 treatment (after 24 weeks, $p=0.05$ ). At baseline the mean osteocalcin (OC) level was normal at $23.6 \pm 1.2 \mathrm{ng} / \mathrm{ml}$. As shown, OC levels increased significantly after 24 weeks $(p=0.03)$ with no further change thereafter in L-T4 treated patients. The mean percentage changes of serum ALP differed significantly between the two treatment groups after 24 weeks $(\Delta 13.2 ; 95 \% \mathrm{CI}, 6.6$ to 19.7 ; $p=0.02$ ). Bone ALP levels were significantly changed after 24 weeks $(\Delta 7.7 \% ; 95 \% \mathrm{CI}, 2.3$ to $13.2 ; p=0.02)$ whereas no differences could be observed for serum OC (Fig. 1).

\section{Bone resorption markers}

At baseline, mean values for urine pyridinoline (PYD, $69.5 \pm 3.4 \mathrm{pmol} / \mathrm{mmol}$ ) and urine deoxypyridinoline (DPD, $13.8 \pm 0.7 \mathrm{pmol} / \mathrm{mmol}$ ) for all 61 women were in the lower part of the reference range for postmenopausal women. During L-T4 treatment, PYD and DPD levels increased progressively with significant changes after 24 weeks $(p=0.003$, for both markers) and 48 weeks $(p=0.016$, and $p=0.014)$. C-Terminal telopeptide type I collagen (CTX) levels were diminished in the whole cohort (CTX; $0.4 \pm 0.02 \mu \mathrm{g} / \mathrm{l})$ at baseline with significant increase in L-T4 treated women after 24 weeks $(p=0.02)$. A comparison of the mean treatment effects between the two treatment groups (L-T4 and placebo) was significant for DPD $(\Delta 16 \% ; 95 \% \mathrm{CI}$,
10.9 to $21.1 ; p=0.001)$ and $\mathrm{CTX}(\Delta 29.9 \% ; 95 \% \mathrm{CI}, 23.3$ to $36.5 ; p=0.002)$ after 24 weeks with no significance thereafter (DPD, $p=0.06$; CTX, $p=0.09$ ) (Fig. 1).

Effect of treatment depending on previous history of hyperthyroidism

To investigate the impact of the nature of underlying thyroid disease as confounding variable on bone metabolism, all study participants were separated based on their past history of hyperthyroidism. Baseline characteristics, including thyroid hormones, markers of bone turnover, and BMD, were not significantly different in women either with (Graves' disease and multinodular goiter; $n=24$ ) or without a past history of hyperthyroidism (Hashimoto's thyroiditis, thyroidectomy for euthyroid goiter; $n=37$ ). The change in bone formation and resorption markers was significantly increased in both L-T4 treatment groups (no hyperthyroidism: ALP, PYD, and DPD, $p=0.02$ / past history of hyperthyroidism: bone ALP and OC, $p=0.03$; PYD, $p=0.004$; DPD, $p=0.006$; CTX, $p=0.01$ ). Interestingly, a comparison of the mean treatment effect revealed a more deleterious effect of thyroid hormone replacement on DPD $(p=0.037)$ in patients with a past history of thyrotoxicosis.

Effect of treatment on bone density measurements

In all women, BMD was measured at baseline and at the end of the study. The mean baseline lumbar BMD for all 

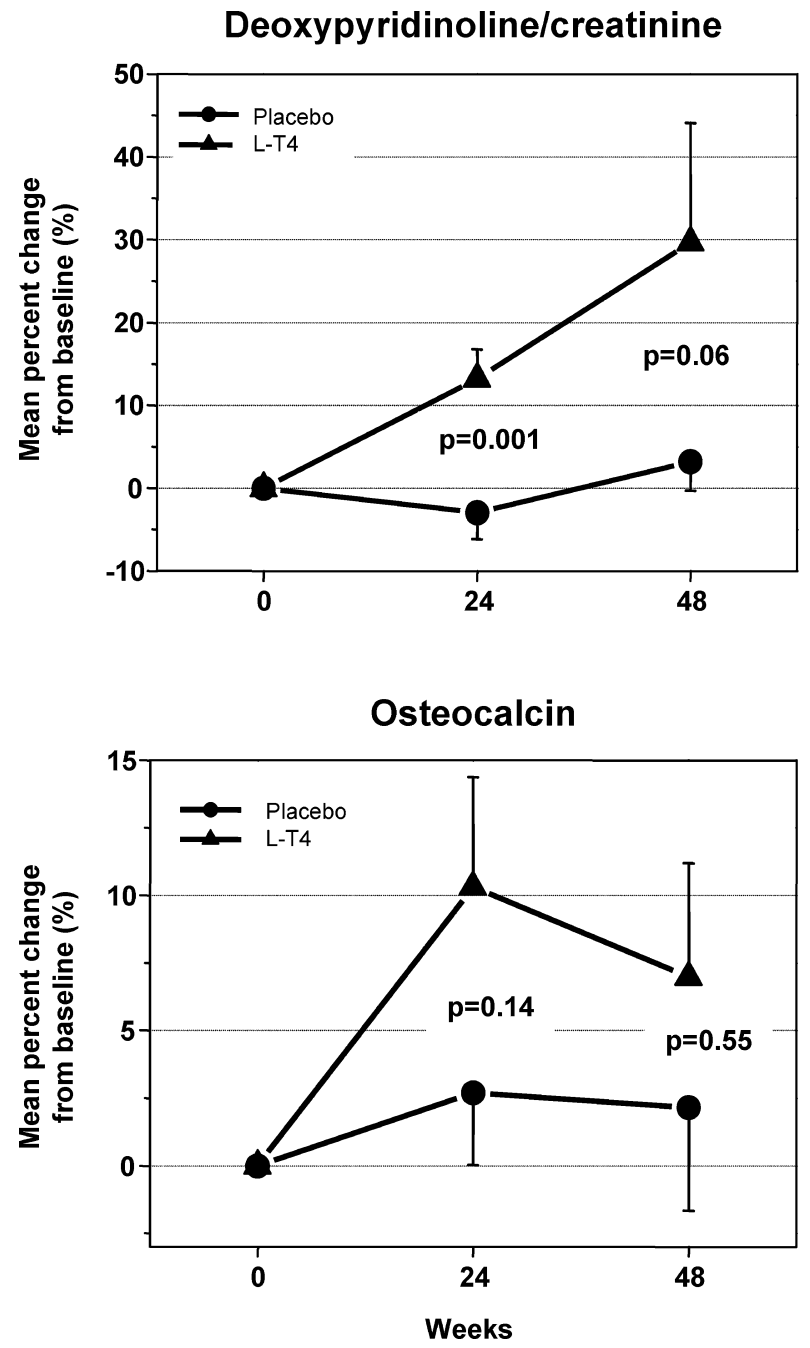

Fig. 1 Effect of L-thyroxine $(n=31)$ and placebo $(n=30)$ on biochemical markers of bone formation (bone ALP, OC) and bone resorption (DPD, CTX). Significance between the treatment groups was assessed by Mann-Whitney $U$-test. The curves show the mean changes $( \pm$ SEM $)$ from baseline

subjects was $1.08 \pm 0.02 \mathrm{~g} / \mathrm{cm}^{2}$ (range 0.68 to $1.64 \mathrm{~g}$ / $\mathrm{cm}^{2}$ ). Expressed as a $Z$-score, the mean bone density was $0.23 \pm 1.15 \mathrm{SD}$ (range -2.70 to $3.56 \mathrm{SD}$ ) above that expected for age and gender. The mean BMD of the femoral neck was $0.92 \pm 0.02 \mathrm{~g} / \mathrm{cm}^{2}$ (range 0.58 to $1.35 \mathrm{~g} / \mathrm{cm}^{2}$ ) with a $Z$-score of $0.42 \pm 0.13 \mathrm{SD}$ (range -1.69 to $3.30 \mathrm{SD}$ ). During L-T4 treatment, significant decrease of BMD was found at the axial skeleton $\left(-0.014 \pm 0.005 \mathrm{~g} / \mathrm{cm}^{2} ;-1.2 \% ; \quad p=0.006\right)$, while no changes were observed at the other sites. In contrast, placebo-treated women showed significant increase of BMD at the trochanter after 48 weeks $\left(0.026 \pm 0.007 \mathrm{~g} / \mathrm{cm}^{2} ; 4 \% ; p=0.002\right)$ and at Ward's triangle $\left(0.049 \pm 0.054 \mathrm{~g} / \mathrm{cm}^{2} ; 5.9 \% ; p=0.0003\right)$, with a trend at the femoral neck $(1.3 \% ; p=0.07)$ and no change at the lumbar spine. A comparison of the mean treatment effect between L-T4 and placebo was significant at the spine $(p=0.029)$, at the trochanter $(p=0.026)$, and at Ward's triangle $(p=0.015$; Table 3$)$.
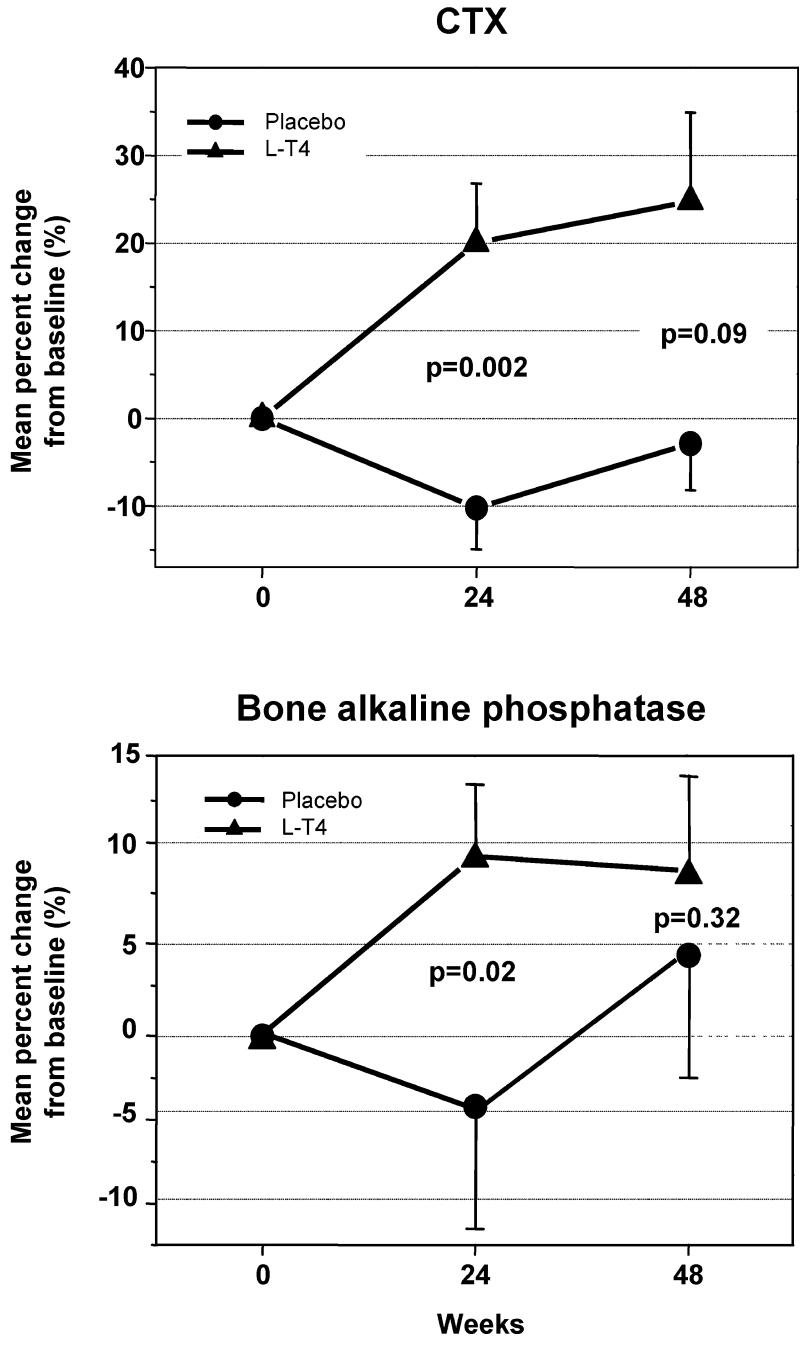

\section{Discussion}

Based on this randomized placebo-controlled study we demonstrate that bone turnover, assessed by biochemical markers of bone formation and resorption, is accelerated during administration of physiological L-thyroxine doses for the correction of thyroid hormone deficiency in women with $\mathrm{SCH}$ as compared to placebotreated controls. Nonetheless, during short-term administration of thyroid hormone replacement the observed increase in bone turnover is associated with only minimal loss of bone density which might not be of clinical relevance in the long term, but can be interpreted as an adaptive mechanism on decreased bone turnover in preexistent subclinical hypothyroidism.

$\mathrm{SCH}$ has been detected with increasing frequency in recent years and is characterized by the finding of elevated TSH levels in the presence of normal circulating thyroid hormones. Though management and treatment of SCH is still matter of debate, recent data showing a beneficial effect of L-thyroxine treatment on clinical and metabolic parameters argues for replacement therapy in at least some of the affected patients [17]. However, data 
Table 3 Mean percentage changes $(95 \% \mathrm{CI})$ in bone mineral density from baseline within groups, and comparison between groups. Significance between the treatment groups was assessed by Student's $t$-test or Mann-Whitney $U$-test in nonparametric distribution, respectively

\begin{tabular}{llll}
\hline Site & Placebo $(n=30)$ & L-Thyroxine $(n=31)$ & Between-group comparison $(p$ value $)$ \\
\hline Lumbar spine & $0.05 \%(-0.8$ to 0.8$)$ & $-1.2 \%(-2.0$ to -0.4$)$ & $p=0.029$ \\
Femoral neck & $1.3 \%(-0.5$ to 3.1$)$ & $0.1 \%(-1.5$ to 1.7$)$ & $p=0.312$ \\
Trochanter & $3.8 \%(1.4$ to 6.2$)$ & $-0.01 \%(-2.1$ to 2.1$)$ & $p=0.026$ \\
Ward's triangle & $5.9 \%(2.6$ to 9.3$)$ & $0.5 \%(-2.5$ to 3.4$)$ & $p=0.015$ \\
\hline
\end{tabular}

are scarce on the early effects of physiological L-thyroxine doses on bone integrity.

The acceleration of bone turnover in $\mathrm{SCH}$ is likely due to the same mechanisms as are known from replacement therapy in overt hypothyroidism. Bone remodeling, characterized by osteoclast-stimulated bone resorption followed by osteoblast-dependent bone remineralization, takes more than half a year to complete in euthyroid condition, and is significantly prolonged to almost 2 years in hypothyroidism [2]. The correction of a hypothyroid state with thyroid hormones may be associated with an increase in new remodeling units. Activation of osteoclast resorptive surfaces might therefore be responsible for transient acceleration of bone turnover during replacement therapy [25]. Hence, our findings of a consistent rise of bone resorption (DPD, PYD, CTX) and formation markers (ALP, bone ALP, OC) might represent an incipient and transient "catch-up" of bone remodeling in SCH. This is consistent with a study by Nyström and coworkers who demonstrated an increase of serum concentrations of procollagen III peptide, a nonspecific marker of early collagen formation, 6 months after the initiation of Lthyroxine therapy in $\mathrm{SCH}$ [18], and with some reports of increased OC and ALP levels in patients with overt hypothyroidism [4, 6, 26]. However, bone markers like OC, ALP, and procollagen I were not altered in other observational studies during the early treatment of overt hypothyroidism $[10,16,27,28]$. Interestingly, in our study, changes in ALP were more pronounced than changes in bone ALP. It has been shown that in the absence of liver disease (which was the case in our study), serum ALP has a higher diagnostic sensitivity than bone ALP to detect changes in bone turnover, while in contrast, bone ALP is more specific for skeletal changes than ALP [29]. We found a consistent rise of bone formation markers after 24 weeks of L-T4 replacement (ALP, $p=0.05$; bone ALP, $p=0.05$; OC, $p<0.05)$. Thereafter only ALP showed a further increase, while bone ALP and OC remained stable. We assume that the later changes may be detected only by the more sensitive ALP measurement.

Based on cross-sectional and longitudinal studies, overtly hypothyroid women who are started on L-thyroxine replacement therapy experience a reduction in both cortical and trabecular bone. During the 1st year of treatment, a bone mineral loss of $5.4 \%$ to $13 \%$ at the lumbar spine $[4,6,7]$ and a loss of $5.1 \%$ to $7 \%$ at the femoral neck $[6,7]$ have been described. This reduction in bone volume has been confirmed in a histomorphometric study using iliac crest biopsies in patients receiving thyroid hormones for 6 months showing that in a hypothyroid state, bone loss is predominantly affected at the cortical site [3]. This is due to the fact that mean cortical bone width is higher than in euthyroid controls as result of decreased bone remodeling in hypothyroidism [2]. However, bone loss seems to be only an adaptive mechanism of newly started thyroid hormone replacement,as in most of the longitudinal studies over 5 to 20 years no significant bone loss was observed during long-term L-thyroxine replacement compared with euthyroid controls [11, 14, 15, 16, 27]. Only one study reported significant loss in bone density in premenopausal women with Hashimoto's thyroiditis during L-thyroxine replacement for an average of 7.5 years. In contrast to the significant reduction of femoral BMD of $7 \%$, no change in lumbar spine bone density was observed [8].

In $\mathrm{SCH}$ we found significant differences of lumbar and femoral bone mineral density between L-T4- and placebo-treated patients after 48 weeks of treatment. This was mainly due to a consistent increase in bone mineral density in placebo-treated patients (at the hip) and a small loss of bone density in L-thyroxine treated women (at the lumbar spine). Therefore we postulate that the observed significant change in BMD is predominantly affected by the lower bone turnover in placebo-treated patients resulting in more mineralized bone, and not due to increased bone resorption in L-T4treated women. Our findings are in agreement with earlier studies that observed a trend toward reduced bone mineral density in L-thyroxine-treated patients with $\mathrm{SCH}[19,20]$, and in accordance, though to a lesser degree, with the changes observed in overt hypothyroidism. Interestingly, as the increases of biochemical markers of bone turnover seen were all within the normal ranges, this was sufficient to produce the changes in BMD seen over 1 year.

Data from the literature indicate that cortical bone seems to be more susceptible to thyroid hormone-induced bone loss than trabecular bone [1]. The percentage of trabecular bone differs markedly between anatomical sites, representing more than $50 \%$ for lumbar spine and femoral trochanter, and about $25 \%$ for femoral neck. Based on the findings of our study, significant decrease in bone mineral density could be observed only in predominantly trabecular sites (lumbar spine, $p=0.029$; trochanter, $p=0.026$ ) and not at cortical sites. This is in 
contrast to patients with hyperthyroidism, who have more bone loss at cortical than trabecular sites.

It remains uncertain whether the observed thyroid hormone-mediated reductions in bone density in hypothyroidism are associated with an increased fracture rate. Results from a recent study evaluating the longterm risk of developing osteoporotic fractures in patients on long-term L-thyroxine treatment is reassuring, as no association with hip fractures was detected [30]. However, as patients have been prospectively followed for 1 year only, a harmful effect of long-term L-T4 replacement on bone turnover and bone mineral density can not be ruled out by this study. In particular this may apply to a less controlled clinical setting with the risk of L-T4 overtreatment.

Our study must be interpreted in the context of its limitations. The major limitation of our study is the short-term follow-up without fracture endpoints. Only larger controlled trial studies will be able to address the question of whether the observed acceleration in bone turnover during the 1st year of L-T4 replacement in patients with $\mathrm{SCH}$ results in an increased fracture rate in the long-term or not. Furthermore, when evaluating the effect of thyroid hormone replacement on bone integrity, a few factors known to influence bone mass have to be taken into account. As this study was controlled for the factors such as gender, age of patients, body mass index, menopausal status and mean age at menopause, intake of drugs interfering with bone metabolism, and smoking habits, special focus has to be put on the nature of underlying thyroid disease. This study is limited by the fact that patients with $\mathrm{SCH}$ were randomized irrespective of their past history of hyperthyroidism, and one could argue that the observed treatment effects might be due to a propensity for increased bone turnover. At study entry, levels of bone markers and BMD in all women were comparable, irrespective of their past history of hyperthyroidism. However, a more deleterious effect of L-thyroxine in patients with a past history of hyperthyroidism cannot be ruled out as DPD levels were significantly more altered in these patients.

In conclusion, we demonstrate by this double-blind, placebo-controlled study that physiological, TSH-guided L-thyroxine treatment accelerates bone turnover in the initial treatment of SCH accompanied by clinically nonsignificant loss of trabecular bone. This may reflect early re-activation of decreased bone remodeling caused by $\mathrm{SCH}$, and not thyroid hormone-induced clinically important bone loss. However, long-term studies are needed to confirm this assumption.

\section{References}

1. Uzzan B, Campos J, Cucherat M, Nony P, Boissel JP, Perret GY (1996) Effects on bone mass of long term treatment with thyroid hormones: a meta-analysis. J Clin Endocrinol Metab 81:4278-4289
2. Eriksen EF (1986) Normal and pathological remodeling of human trabecular bone: three dimensional reconstruction of the remodeling sequence in normals and in metabolic bone disease. Endocr Rev 7:379-408

3. Coindre JM, David JP, Riviere L, Goussot JF, Roger P, de Mascarel A, Meunier PJ (1986) Bone loss in hypothyroidism with hormone replacement: a histomorphometric study. Arch Intern Med 146:48-53

4. Krolner B, Jorgensen JV, Nielsen SP (1983) Spinal bone mineral content in myxoedema and thyrotoxicosis: effects of thyroid hormone(s) and antithyroid treatment. Clin Endocrinol (Oxf) 18:439-446

5. Paul TL, Kerrigan J, Kelly AM, Braverman LE, Baran DT (1988) Long-term L-thyroxine therapy is associated with decreased hip bone density in premenopausal women. JAMA 259:3137-3141

6. Ribot C, Tremollieres F, Pouilles JM, Louvet JP (1990) Bone mineral density and thyroid hormone therapy. Clin Endocrinol (Oxf) 33:143-153

7. Greenspan SL, Greenspan FS, Resnick NM, Block JE, Friedlander AL, Genant HK (1991) Skeletal integrity in premenopausal and postmenopausal women receiving long-term L-thyroxine therapy. Am J Med 91:5-14

8. Kung AW, Pun KK (1991) Bone mineral density in premenopausal women receiving long-term physiological doses of levothyroxine. JAMA 265:2688-2691

9. Campos-Pastor MM, Munoz-Torres M, Escobar-Jimenez F, Ruiz de Almodovar M, Jodar Gimeno E (1993) Bone mass in females with different thyroid disorders: influence of menopausal status. Bone Miner 21:1-8

10. Garton M, Reid DM, Loveridge N, Robins S, Murchison L, Beckett G, Reid D (1994) Bone mineral density and metabolism in premenopausal women taking L-thyroxine replacement therapy. Clin Endocrinol (Oxf) 41:747-755

11. Hanna FW, Pettit RJ, Ammari F, Evans WD, Sandeman D, Lazarus JH (1998) Effect of replacement doses of thyroxine on bone mineral density. Clin Endocrinol (Oxf) 48:229-234

12. Grant DJ, McMurdo ME, Mole PA, Paterson CR, Davies RR (1993) Suppressed TSH levels secondary to thyroxine replacement therapy are not associated with osteoporosis. Clin Endocrinol (Oxf) 39:529-533

13. Duncan WE, Chang A, Solomon B, Wartofsky L (1994) Influence of clinical characteristics and parameters associated with thyroid hormone therapy on the bone mineral density of women treated with thyroid hormone. Thyroid 4:183-190

14. Franklyn J, Betteridge J, Holder R, Daykin J, Lilley J, Sheppard M (1994) Bone mineral density in thyroxine treated females with or without a previous history of thyrotoxicosis. Clin Endocrinol (Oxf) 41:425-432

15. Schneider DL, Barrett-Connor EL, Morton DJ (1994) Thyroid hormone use and bone mineral density in elderly women: effects of estrogen. JAMA 271:1245-1249

16. Hawkins F, Rigopoulou D, Papapietro K, Lopez MB (1994) Spinal bone mass after long-term treatment with L-thyroxine in postmenopausal women with thyroid cancer and chronic lymphocytic thyroiditis. Calcif Tissue Int 54:16-19

17. Cooper DS (2001) Clinical practice: subclinical hypothyroidism. N Engl J Med 345:260-265

18. Nystrom E, Caidahl K, Fager G, Wikkelso C, Lundberg PA, Lindstedt G (1988) A double-blind cross-over 12-month study of L-thyroxine treatment of women with 'subclinical' hypothyroidism. Clin Endocrinol (Oxf) 29:63-75

19. Ross DS (1993) Bone density is not reduced during the shortterm administration of levothyroxine to postmenopausal women with subclinical hypothyroidism: a randomized, prospective study. Am J Med 95:385-388

20. Jaeschke R, Guyatt G, Gerstein H, Patterson C, Molloy W, Cook D, Harper S, Griffith L, Carbotte R (1996) Does treatment with L-thyroxine influence health status in middle-aged and older adults with subclinical hypothyroidism? J Gen Intern Med 11:744-749 
21. Pines A, Dotan I, Tabori U, Villa Y, Mijatovic V, Levo Y, Ayalon D (1999) L-thyroxine prevents the bone-conserving effect of HRT in postmenopausal women with subclinical hypothyroidism. Gynecol Endocrinol 13:196-201

22. Meier C, Staub JJ, Roth CB, Guglielmetti M, Kunz M, Miserez AR, Drewe J, Huber P, Herzog R, Muller B (2001) TSH-controlled L-thyroxine therapy reduces cholesterol levels and clinical symptoms in subclinical hypothyroidism: a double blind, placebo-controlled trial (Basel Thyroid Study). J Clin Endocrinol Metab 86:4860-4866

23. Garnero P, Borel O, Delmas PD (2001) Evaluation of a fully automated serum assay for C-terminal cross-linking telopeptide of type I collagen in osteoporosis. Clin Chem 47:694-702

24. Gluer CC, Blake G, Lu Y, Blunt BA, Jergas M, Genant HK (1995) Accurate assessment of precision errors: how to measure the reproducibility of bone densitometry techniques. Osteoporos Int 5:262-270

25. Ross DS (1991) Monitoring L-thyroxine therapy: lessons from the effects of L-thyroxine on bone density. Am J Med 91:1-4
26. Bergmann P, Dediste A, Demeester-Mirkine N, Deconinck I, Corvilain J (1989) Serum bone Gla protein (BGP) in primary hypothyroidism before and during treatment with thyroid hormones. Horm Metab Res 21:47-48

27. Gam AN, Jensen GF, Hasselstrom K, Olsen M, Nielsen KS (1991) Effect of thyroxine therapy on bone metabolism in substituted hypothyroid patients with normal or suppressed levels of TSH. J Endocrinol Invest 14:451-455

28. Campbell J, Day P, Diamond T (1996) Fine adjustments in thyroxine replacement and its effect on bone metabolism. Thyroid 6:75-78

29. Woitge HW, Seibel MJ, Ziegler R (1996) Comparison of total and bone-specific alkaline phosphatase in patients with nonskeletal disorder or metabolic bone diseases. Clin Chem 42:1796-1804

30. Sheppard MC, Holder R, Franklyn JA (2002) Levothyroxine treatment and occurrence of fracture of the hip. Arch Intern Med 162:338-343 